\title{
Thermionic Electron Gun Design and Prototyping
}

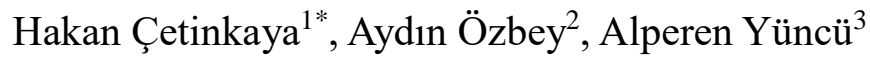 \\ 1* Dumlupınar Üniversitesi, Fen Edebiyat Fakültesi, Fizik Bölümü, Kütahya, Türkiye (ORCID: 0000-0002-1466-5930), hcetinkaya@ gmail.com \\ 2 İstanbul Üniversitesi-Cerrahpaşa Üniversitesi, Mühendislik Fakültesi, Makine Mühendisliği Bölümü, İstanbul, Türkiye (ORCID: 0000-0001-7097-4044), \\ ozbeya@istanbul.edu.tr \\ ${ }^{3}$ Ruprecht-Karls-Universität Heidelberg, Physikalische Insitute, Heidelberg, Almanya (ORCID: 0000-0001-9696-9331), ayuncu@ @ern.ch
}

(First received 14 October 2020 and in final form 9 April 2021)

(DOI: 10.31590/ejosat.809155)

ATIF/REFERENCE: Çetinkaya, H., Özbey, A. \& Yüncü, A. (2021). Thermionic electron gun design and prototyping. European Journal of Science and Technology, (23), 702-709.

\begin{abstract}
A prototype thermionic electron gun is designed and produced at Bogazici University's KAHVE Laboratory to gain experience on electron sources towards industrial electron beam applications. The electron gun includes a thoriated tungsten filament, a Wehnelt cup, an anode, a Faraday cup and a solenoid. Electron gun simulations were performed by using the IBSimu program. The produced electron gun is operating at $20 \mathrm{kV}$ and produces beam currents up to $3 \mathrm{~mA}$. This paper reports the experimental results and encountered problems during the construction of the thermionic electron gun.
\end{abstract}

Keywords: Particle sources, simulation, solenoid magnet

\section{Termiyonik Elektron Tabancası Tasarımı ve Prototip üretimi}

$\ddot{O} \mathbf{z}$

Boğaziçi Üniversitesi KAHVE Laboratuvarı'nda prototip termiyonik electron tabancası, endüstriyel elektron demeti uygulamalarında deneyim kazanmak amacıyla tasarlanmış ve üretilmiştir. Elektron tabancası toryum kaplı tungsten filament, Wehnelt bardağı, Faraday bardağı ve solenoid bileşenlerinden oluşmaktadır. Elektron tabancası benzetimleri IBSimu isimli program kullanılarak gerçekleştirilmiştir. Üretimi gerçekleştirilen elektron tabancası, $20 \mathrm{kV}$ potansiyel ve $3 \mathrm{~mA}$ 'e kadar demet akımında çalışmaktadır. Bu çalışma, termiyonik elektron tabancasının üretimi sırasında karşılaşılan sorunları ve deneysel sonuçları raporlamaktadır.

Anahtar Kelimeler: Parçacık kaynakları, benzetim, solenoid mıknatıs.

\footnotetext{
* Corresponding Author: hcetinkaya@gmail.com
} 


\section{Introduction}

Natural radioactive materials and man-made radiation sources are used in various areas of our life ranging from industry to medicine. Natural radioactive materials have applications like production of wood - plastic composites by gamma irradiation induced polymerization, degradation of PTFE, polymer flocculant, synthesis of chemicals, sterilization, food irradiation Machi, Yuan, \& Sevastyanov, 1983; Bakrajia, Salmana \& Al-kassirib, 2001). As the usability of natural radioactive sources are limited, artificial radiation sources, like electron and ion accelerators, are invented and used since the early 20th century.

Electrons and protons have different properties, therefore both are accelerated and used in different areas. Electrons approach the speed of light after just a few MeV energy gain, corresponding to a few meters of acceleration, the rest of the accelerating structure becomes periodic. Protons acceleration is much slower thus the proton machines are much longer than their electron counterparts and the accelerating structure needs to differ in each acceleration step (Vretenar, 2005). Some industrial applications of the electron accelerators up to $10 \mathrm{MeV}$ are surface curing, shrink film, wire and cable insulation, sterilization, food irradiation, tires, electron microscopes, melting, welding, drilling, disinfection, coating, etc.. (International Irradiation Association (IIA), 2011; Studer, 1990; Eucard-2, 2017). Ion accelerators with energies up to few MeVs have applications in air pollution reduction, in archaeo-geology, in the semiconductor industry, in proton-beam writing, in nanomaterials and polymers (Eucard-2, 2017; Barbalat, 1990; Bhandari \& Malay Kanti Dey, 2011). It is necessary to produce electron and ion beams before any acceleration could occur. Electron and ion beams can be generated with different techniques and therefore a particle source is the general name for both electron and ion sources.

Particle sources are the most basic nevertheless the most important structure of the both electron (electron gun) and ion (ion source) accelerators. The properties of the beam needed by relevant application are determined by the particle sources, and it is important for the rest of accelerator structure. Particle source design requires special attention and work experience (Scrivens, 2003).

A cathode is a metal that emits electrons from its surface. There are different types of cathodes like hot (directly and indirectly heated) and cold cathode (Radio Corporation of America, Electron Tube Division (RCA), 1943; Iqbal \& Aleem, 2005). Beam parameters are directly related to the cathode and gun design. The physical phenomena of beam generation can be classified as Thermionic emission, high field emission and photo emission (Iqbal et al., 2005). Thermionic electron guns are mostly used in industrial accelerators (Nazari, Abbasi, Ghasemi, Haghalab \& Ahmadiannanim, 2017) and the rest of the paper will focus on it.

Tungsten and LaB6 cathodes are examples of cathodes that are used as an electron source in the thermionic electron guns. These met requirements for emission capability, ease of maintenance, low cost and also ease of finding the supplies. A filament is heated until the energy of electrons inside the cathode is enough to overcome the work function, then the electrons are emitted into the vacuum environment. Liberated electrons are pushed towards the anode by applying an electric field between cathode and anode (typically thousands of volts) (RCA, 1943; Iqbal et al., 2005; Koqure, 2013). The lifetime of the cathode is important for the stable operation of the electron gun. The total operation time depends on the evaporation of the filament which itself depends on the filament heater current (beam current), wire diameter, wire length, cathode heating time, etc (RCA, 1943; Virag \& Murin, 2008). It is assumed that filament lifetime ends when $10 \%$ of the material is evaporated (Harbough, 1962). It was found out by Langmuir that mixing thorium oxide (thoria) with pure tungsten increases the emission capacity of the filament. Thoria percentage is typically around 1 to $2 \%$. Pure tungsten has a work function of $4.5 \mathrm{eV}$ whereas thoriated tungsten has a work function of $2.63 \mathrm{eV}$. Pure tungsten cathode works around $2700 \mathrm{~K}$ and thoriated tungsten cathodes works around $2000 \mathrm{~K}$ (RCA, 1943; Harbough, 1962).

Kandilli Detector, Accelerator and Instrumentation (KAHVE) Laboratory, aiming to develop particle detectors and particle accelerators, is located at the Bogazici University Kandilli Campus, in Istanbul, Turkey. A prototype of $20 \mathrm{keV}$, thermionic electron gun with thoriated tungsten filament is designed, developed and tested in KAHVE Laboratory with an aim of gaining experience on electron gun for later development of industrial applications like electron beam welding, electron microscope and high energy electron accelerators.

\section{Prototype Design}

The prototype consists of a filament, a Wehnelt cup, an anode, a solenoid to focus the electron beam and a Faraday cup. Acrylic glass and Pyrex glass is used as a vacuum chamber. A thorium coated tungsten, denoted as $\mathrm{W}(\mathrm{Th})$, wire is used as a filament. The filament is heated by using a variac and held at negative voltage with respect to ground. A special made isolation transformer is used between variac and high voltage power supply. Series of resistors are connected between the Wehnelt cup and filament for self-bias. Self-bias is used to stabilize the beam current by producing a negative feedback loop (Munakata $\&$ Watanabe, 1962). Anode is held at ground voltage. A solenoid is designed and produced to focus the beam. A simple, long faraday cup is used to measure the beam current.

There are various simulation programs to help with the electron source design by tracking particles; some examples are CST, Egun, IBSimu, etc (Lee, Kim, Ghergherehchi, Shin, Lee, Y.S., Yeon, Lee, B.N. \& Chai, 2014; Herrmannsfeldt, 1997; Kalvas, Tarvainen, Ropponen, Steczkiewicz, Ärje \& Clark, 2010). For this prototype, simulations were performed to understand the behaviour of the beam before the production stage was started (Hoseinzade, Nijatie, \& Sadighzadeh, 2016).

\subsection{Electron Gun Simulation}

Electron gun design is performed by using the C++ IBSIMU program, which is actually used for ion beam extraction from plasma. It can also be used to track charged particles like electrons. The program can track particles in 2 dimensional, 3 dimensional and in cylindrical coordinates. It solves Poisson Equation by using the finite difference method by including the space charge effect (Kalvas et al., 2010).

Cylindrical coordinates are used in the simulations for simplicity. Number of particle trajectories, beam current density, beam dimensions, beam divergence, beam geometry, particle 
starting energy, electrical potentials and magnetic field if available are some of the required input parameters for IBSimu.

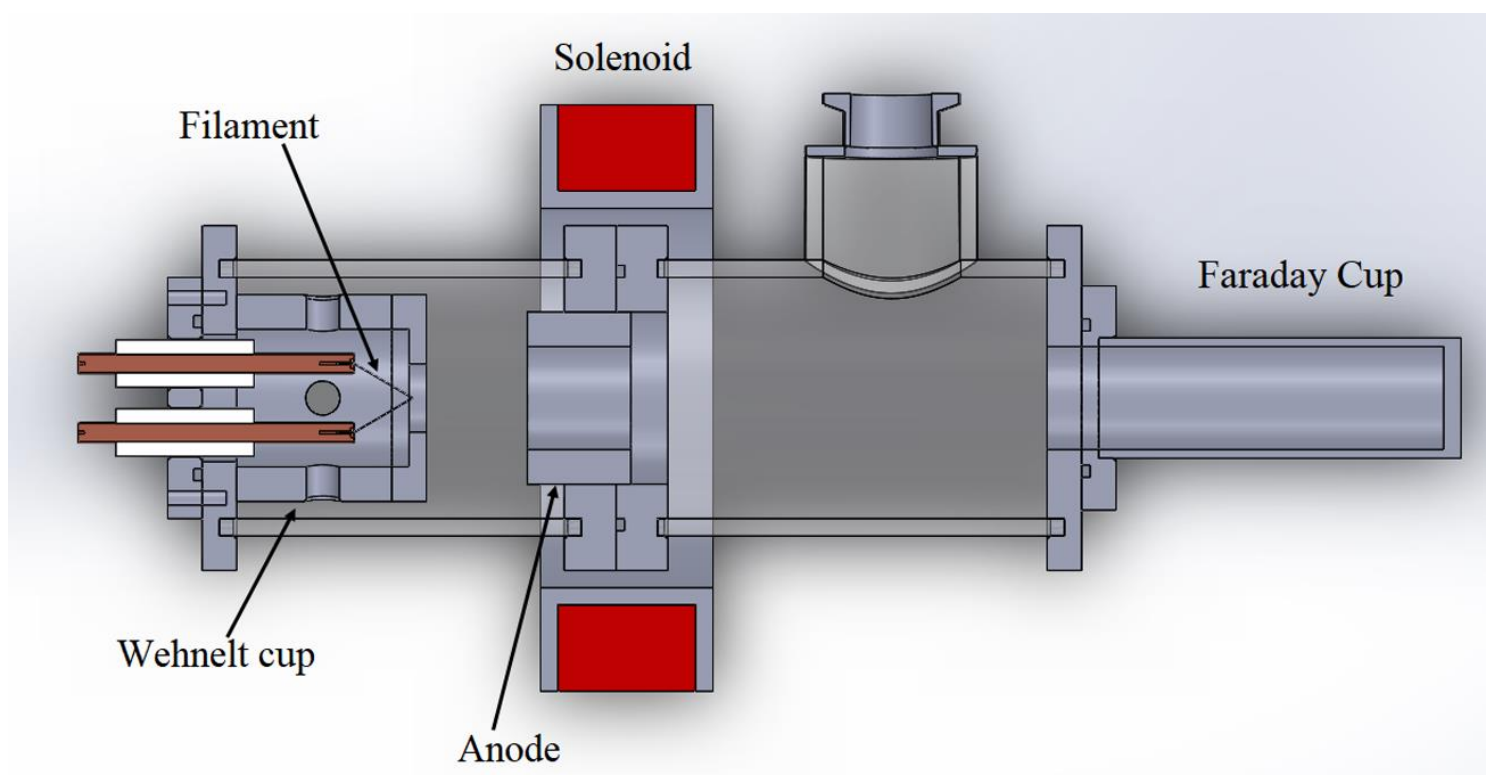

Fig. 1. Schematic of prototype Thermionic electron gun

It is not possible to define the surface for electron emission in IBSimu so the electrons emitting from the filament is defined as a point source by assuming that it is equal to filament radius. The emitted maximum current density is given by RichardsonDushman equation (Iqbal et al., 2005; Harbough, 1962):

$$
\mathrm{J}=\mathrm{AT}^{2} \mathrm{e}^{((-\mathrm{W} / \mathrm{kT}))}
$$

where $\mathrm{J}$ is the emission current density, $\mathrm{A}$ is the Richardson constant and typically $3\left(\mathrm{~A} . \mathrm{cm}^{-2} \cdot \mathrm{K}^{-2}\right)$ for thoriated tungsten, $\mathrm{T}$ is the temperature of filament $(\mathrm{K}), \mathrm{W}$ is the work function of material $(\mathrm{eV})$ and $\mathrm{k}$ is the Boltzmann constant.
Current densities are calculated by using RichardsonDushman equation (Iqbal et al., 2005; Harbough, 1962) for thoriated tungsten for different temperatures which are given in Table 1 and then used as an input for IBSimu.

Electron beam trajectory was initially calculated as in Figure 2 for $20 \mathrm{kV}$ potential difference and the diverging beam was seen at the Faraday cup location. It was therefore determined that a solenoid was required to focus the beam.

Table 1. Current densities calculated by Richardson-Dushman equation for thoriated tungsten filament

\begin{tabular}{c|c}
\hline $\begin{array}{c}\text { Filament Temperature } \\
(\mathbf{K})\end{array}$ & $\begin{array}{c}\text { Current Density } \\
\left(\mathbf{A} / \mathbf{m}^{\mathbf{2}}\right)\end{array}$ \\
\hline 1500 & 94.4 \\
\hline 1600 & 384.1 \\
\hline 1700 & 1335 \\
\hline 1800 & 4065.8 \\
\hline 1900 & 11077.8 \\
\hline 2000 & 27448.3 \\
\hline
\end{tabular}

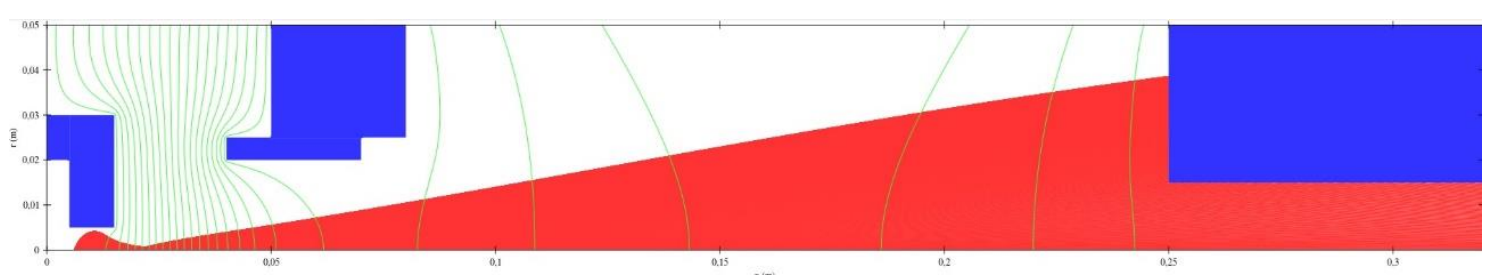

Fig. 2. Electron beam trajectory 


\subsection{Magnetic Field Design}

A magnetic field map is generated by using the Poisson Superfish program and imported to IBSimu. A solenoid was tested in different locations. Electron trajectories can be seen from Figure 3 when the solenoid magnetic field map was imported.

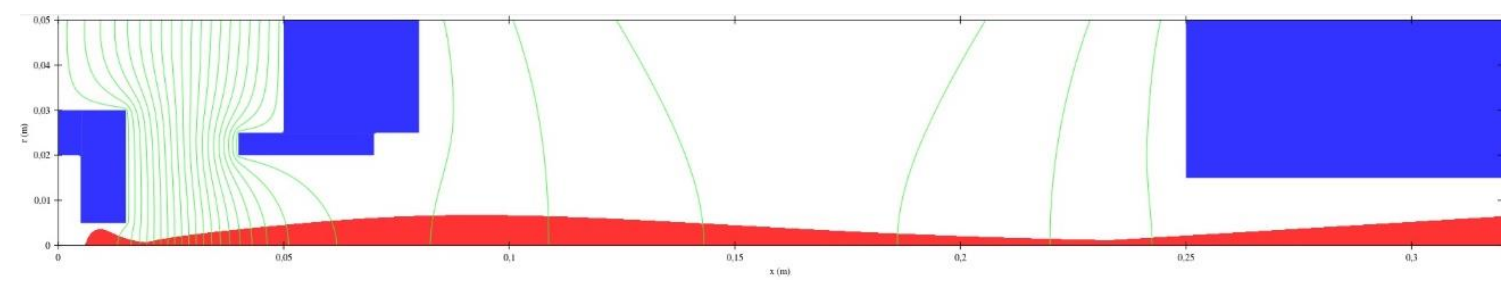

Fig. 3. Electron beam trajectory with magnetic field.

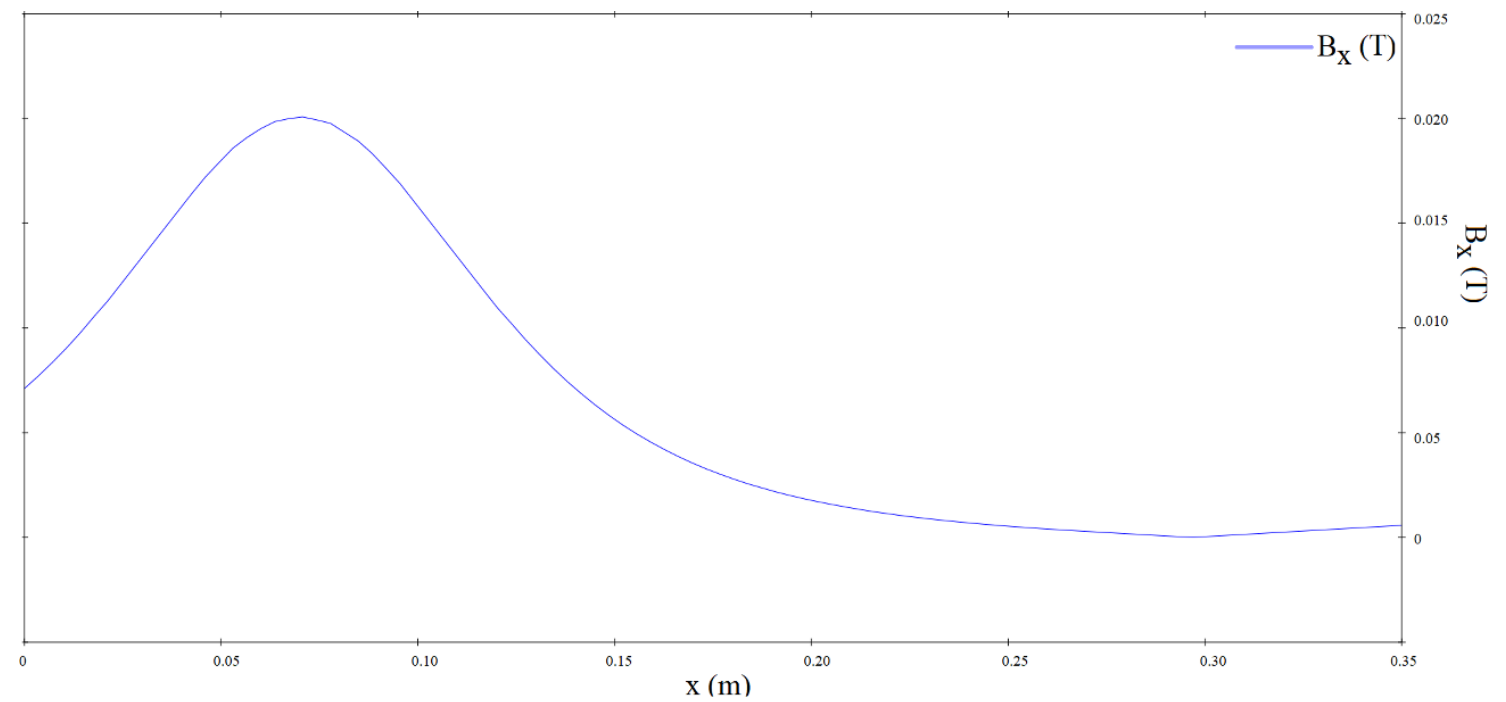

Fig. 4. Magnetic field imported to electron gun design

Two different solenoids were designed for the tests by using Poisson Superfish program (Billenand \& Young, 1987). First solenoid has an inner radius of $70 \mathrm{~mm}$, length $45 \mathrm{~mm}$ with a 384 turns which was winded around the teflon pulley with a copper diameter of $2.8 \mathrm{~mm}$. Hereafter, this solenoid will be mentioned as solenoid-A. Trials were conducted with solenoid currents of 6 to 11 A's and after sometime, it was determined that teflon pulley of the design-A was started to melt down because of high temperature and it was getting hard to center the beam. Later it was decided to measure the coil magnetic field to understand the problem. It is seen from Figure 5 that the solenoid magnetic field was shifted because of the heat melting the pulley.

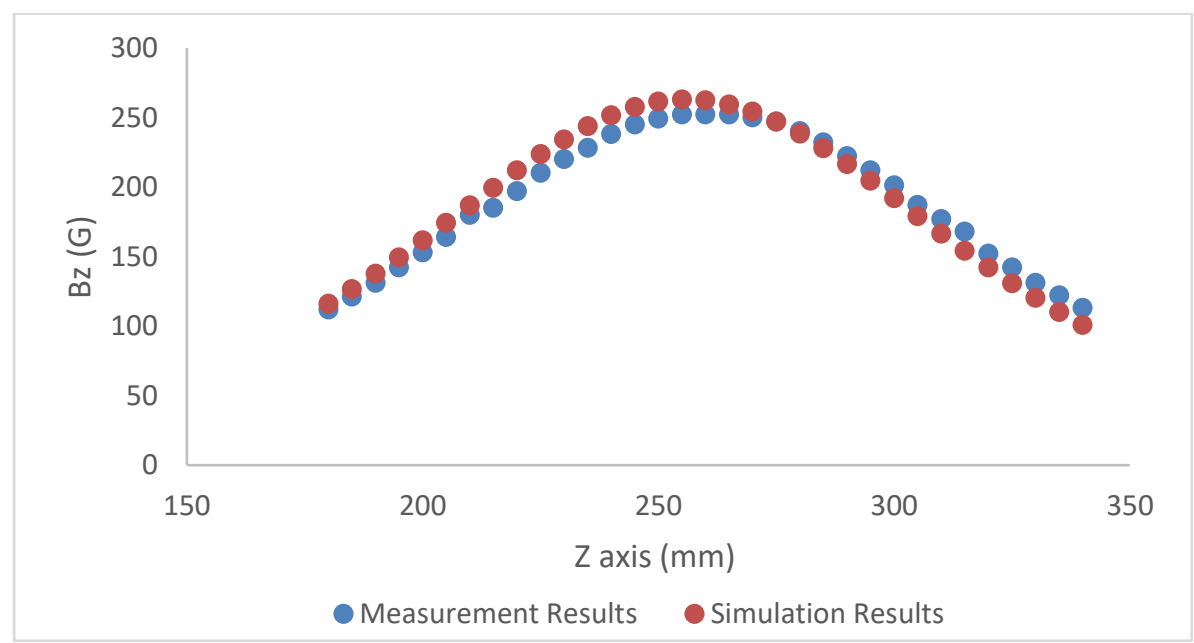

Fig. 5. Solenoid design-A magnetic field comparison between simulation and measurement 
Later a new solenoid was designed labeled as solenoid design-B. Second solenoid has an inner radius of $60 \mathrm{~mm}$, length $40 \mathrm{~mm}$ with an 800 turns which was winded around the aluminum pulley with a coil diameter of $1 \mathrm{~mm}$, inside of the aluminum pulley is covered with teflon, this solenoid will be mentioned as solenoid-B. Teflon was initially used as a pulley to prevent sparks between the metallic components and the solenoid because initially it was thought that solenoid can be placed to different locations where high voltage can be found. The magnetic field of the solenoid was measured after fabrication. These measurements were performed to verify the simulation results. Simulation and measurement comparison results are given in Figure 6. It is seen that the simulated and measured magnetic fields are in good agreement with each other.

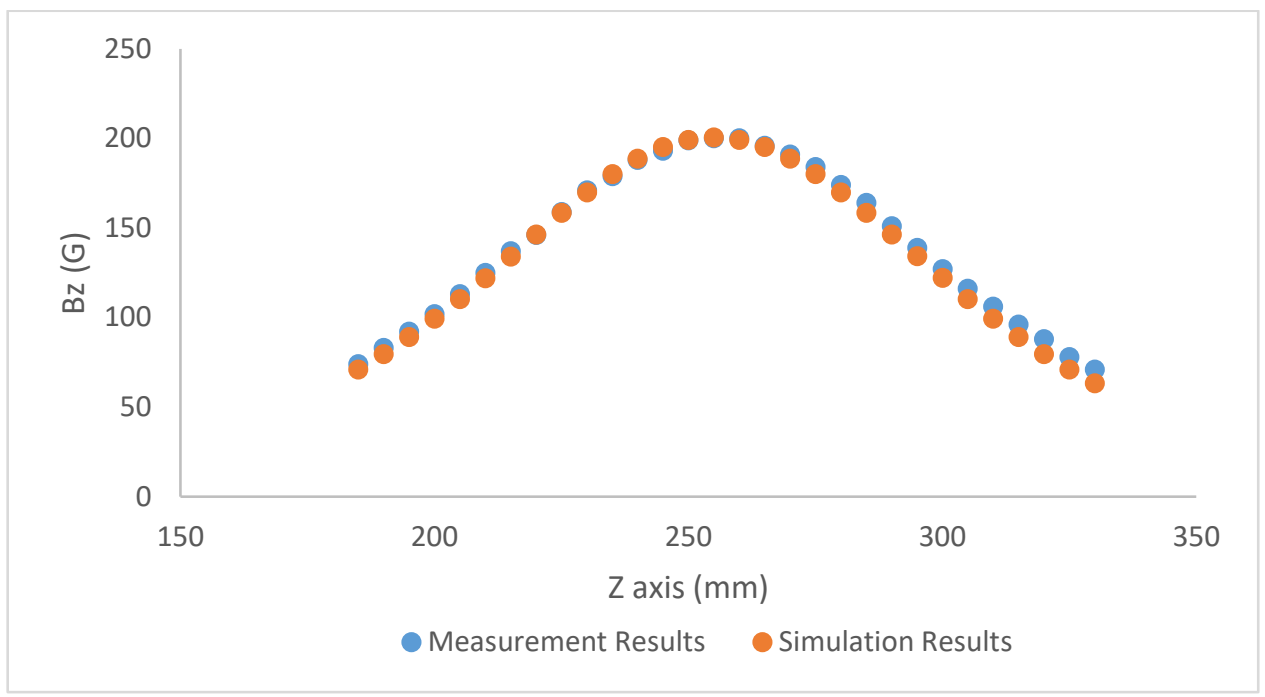

Fig. 6. Solenoid design-B magnetic field comparison between simulation and measurement

\section{Experimental Results}

System was tested for the vacuum at the initial stage. Vacuum was measured from the output of the vacuum port by using KF25 tee by using Edwards WRG-S-NW25 vacuum gauge. Vacuum is around $9 \times 10^{-6}$ mbar level before starting the tests. After that, the system was tested for high voltage and no sparks were detected.

A long Faraday cup was used to measure beam current to prevent the escape of electrons because it can be resulted as positive or negative beam current readings (Bahrami, Yasrebi \& Rashidian, 2009). Faraday cup does not have any biasing ring. A dc ammeter was connected to Faraday cup for beam current readings. A second ammeter was also connected to the anode to detect the hitting particles. A pens ammeter was placed between variac and filament to detect filament current.

First tests were performed by using pure tungsten filament with a diameter of $0.51 \mathrm{~mm}$ and $0.25 \mathrm{~mm}$ but it required too much filament current (about 9A and above) for high beam currents, generates too much heat and we had problems in acrylic and pyrex glass. Our design was not suitable for this. Pure tungsten filament also becomes too fragile when we try to change its location after heating.

Later the filament was changed with thoriated tungsten that has a $1 \%$ thorium and $99 \%$ tungsten. Filament was heated slowly and then high voltage was applied to the Wehnelt cup. The photo of the fabricated electron gun during operation can be seen in Figure 7.

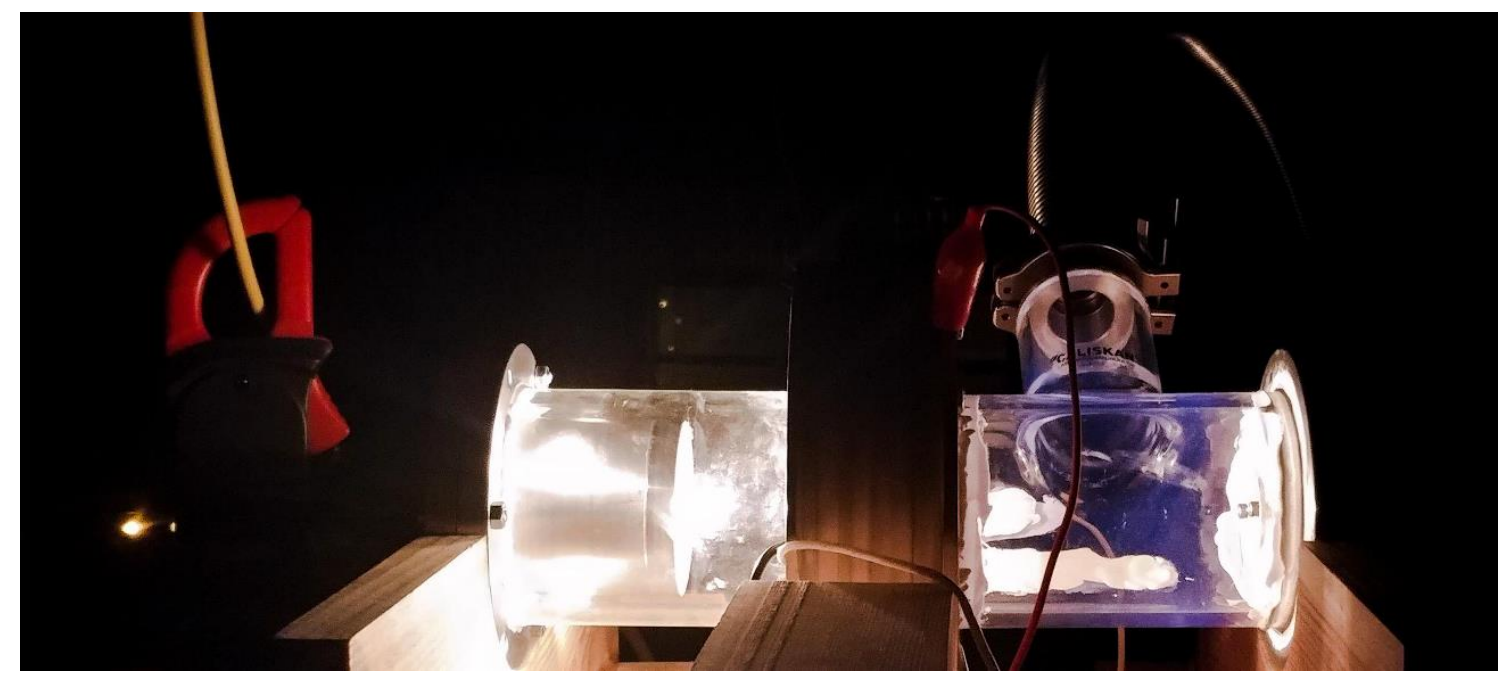

Fig. 7. Fabricated electron gun 
Filament shape, filament current and self-biasing resistance values were determined after trials for best configuration. Determination of filament temperature was not the part of this study so it was not measured. Some results are given in Table 2 and Table 3 which were made in the same configuration. Differences between configurations are the replacement of the filament due to its overheating and the solenoid used in experiments.

Beam currents up to $3 \mathrm{~mA}$ were measured. It is seen from the Table 2 that higher beam currents were achieved with lower resistance values used for self-bias. Electron gun can run up to half hours with high beam currents but cooling is necessary for higher operation times. It is also determined that acrylic and Pyrex glass is not useful for high beam currents also for industrial applications.

Current measurements were performed in the anode electrode and up to $0.6 \mathrm{~mA}$ is measured. It is later determined that it is caused because of the misalignment of the solenoid, anode electrode and filament. Filament shape can be seen in Figure 8.

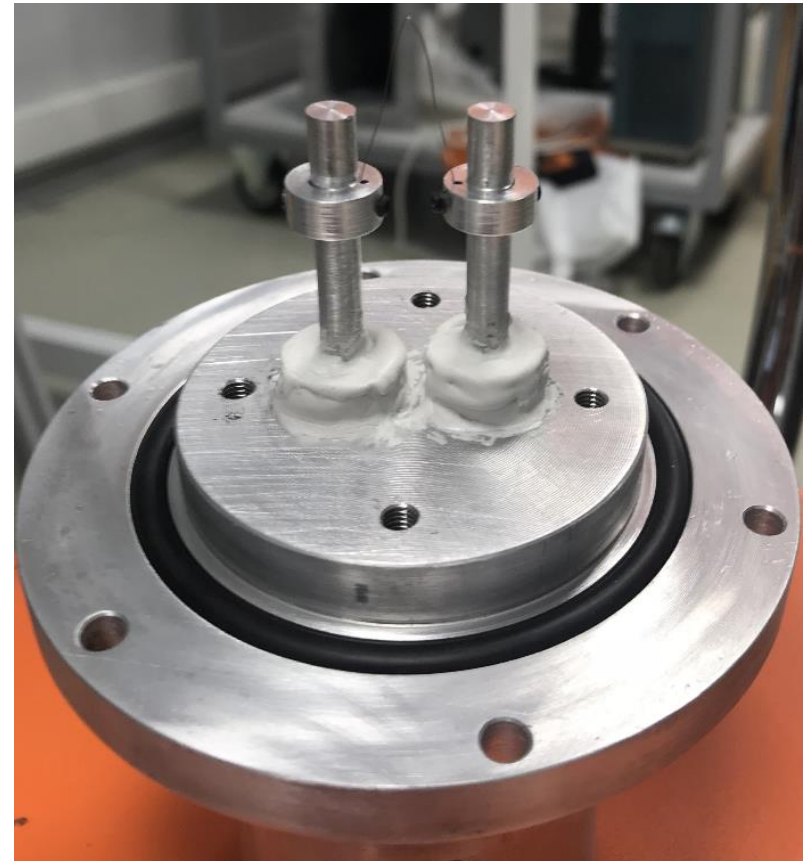

Fig. 8. Filament connections

Table 2. Electron beam current measurements by using solenoid A

\begin{tabular}{|c|c|c|c|c|c|}
\hline $\begin{array}{c}\text { Filament current } \\
(\mathbf{A})\end{array}$ & $\begin{array}{c}\mathbf{R} \\
(\mathbf{k O h m})\end{array}$ & $\begin{array}{c}\text { Wehnelt Voltage } \\
(\mathbf{k V})\end{array}$ & $\begin{array}{c}\text { Solenoid current } \\
(\mathbf{A})\end{array}$ & $\begin{array}{c}\text { Beam current } \\
(\mathbf{m A})\end{array}$ & $\begin{array}{c}\text { Anode current } \\
(\mathbf{m A})\end{array}$ \\
\hline 2.71 & 10 & 20 & 7.37 & 2.4 & 0.6 \\
\hline 2.74 & 50 & 20 & 7.82 & 1.19 & 0.19 \\
\hline 2.71 & 100 & 20 & 9.86 & 0.7 & 0.098 \\
\hline 2.71 & 200 & 20 & 10.78 & 0.47 & 0.078 \\
\hline 2.71 & 300 & 20 & 7.82 & 0.35 & \\
\hline
\end{tabular}

Table 3. Electron beam current measurements by using solenoid B

\begin{tabular}{|c|c|c|c|c|c|}
\hline $\begin{array}{c}\text { Filament current } \\
(\mathbf{A})\end{array}$ & $\begin{array}{c}\mathbf{R} \\
(\mathbf{k o h m})\end{array}$ & $\begin{array}{c}\text { Wehnelt voltage } \\
(\mathbf{k V})\end{array}$ & $\begin{array}{c}\text { Solenoid Current } \\
(\mathbf{A})\end{array}$ & $\begin{array}{c}\text { Beam } \\
\text { current (mA) }\end{array}$ & $\begin{array}{c}\text { Anode } \\
\text { current }(\mathbf{m A})\end{array}$ \\
\hline 2.53 & 20 & 20 & 2.50 & 1.23 & 0.35 \\
\hline 2.63 & 20 & 20 & 2.94 & 1.77 & 0.386 \\
\hline 2.74 & 20 & 20 & 2.94 & 2.78 & 0.6 \\
\hline
\end{tabular}


A phosphorous screen was prepared and placed at the Faraday cup location to measure the beam spot size but the measurement was not successful as the screen was damaged due to high current when beam focused. Instead of this method, the beam was focused on a metal surface and heated, after sometime, the beam spot size becomes visible as seen in Figure 9. A copper surface was used at first tests as seen in Figure 7, a plasma was formed at the Faraday Cup side and afterwards it was decided not to use it.

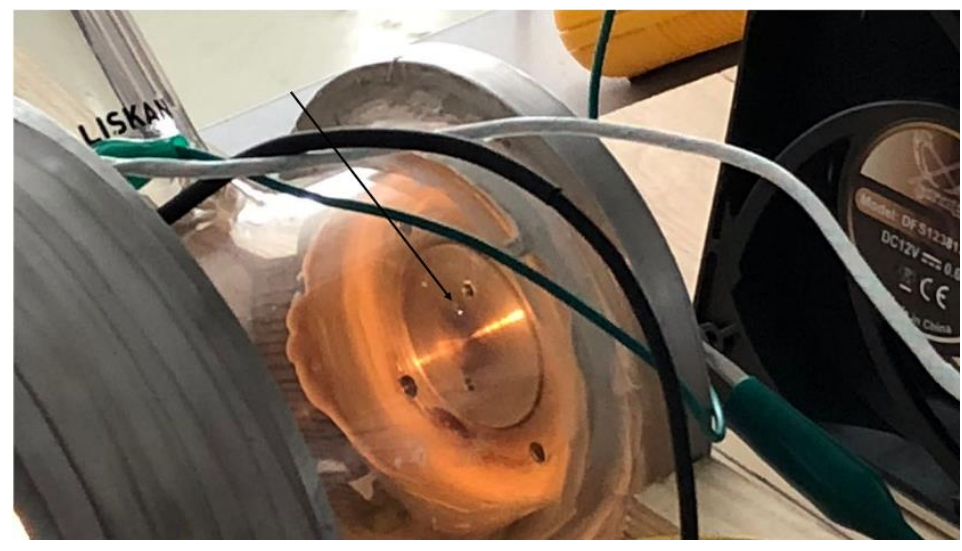

Fig. 9. Beam spot size shown by the black arrow

\section{Discussion}

The prototype was built to increase the know-how of our laboratory for future studies with a low budget and we faced several problems to fix for the future results. There are limitations for this prototype essentially because of excessive heating:

- The solenoid's magnetic field drops because of heat as a result of longer operation times and a water cooling system is required.

- The pyrex glass can easily be damaged during the heat exchanges. More sturdy materials like alumina and ceramic should be considered for further studies.

There is also an outgassing problem in the acrylic glass used as a vacuum chamber and it is not good for vacuum.

The method of shaping the filaments by hand was finally found as a non-reliable method: it causes misalignment between the beam and beamline components, therefore becoming one of the error sources. It is also not repeatable. A more reliable method for shaping the filaments will be developed.

We measured the beam current with Faraday Cup, but it does not have a biasing electrode, this brings some doubts on the measurement results. A new Faraday Cup has to be designed with a biasing electrode, making it much more reliable.

There are also major differences between the simulation results and experimental measurements. Although the simulations give some information, they do not reflect the real world situations. The differences are mostly caused by misalignment (human error) issues. It is planned to place the deflection coils (steerer magnets) to fix the misalignments for future studies; the current prototype version does not have enough space for the steerer magnets. Additionally, the filament temperature to be measured for a realistic comparison.

Beam spot size measurements with phosphorus screens failed because of excessive electron beam power (between 20 to 60 Watt's) and a metal plate was used to determine the beam focusing. Scintillator screen for high powers has to be used for a better understanding.

In summary, beam currents up to $3 \mathrm{~mA}$ are measured by using W(Th) filament. Higher beam currents required for industrial applications and longer operation times. This study has reached its purpose for this stage. The problems mentioned above should be solved for the next phase.

\section{Acknowledge}

This study is supported by Bogazici University Scientific Research Commission Project No: 11481. The authors are grateful to KAHVE Laboratory members and specially to E. Ergenlik, for their support. They would also like to thank G. Turemen and U. Kaya for their technical support and G. Unel for a careful reading of this manuscript.

\section{References}

Bakrajia, E.A., Salmana, N. \& Al-kassirib, H. (2001). Gamma radiation induced wood-plastic composites from Syrian tree species. Radiation Physics and Chemistry, 61: 137-141. https://dx.doi.org/10.1016/S0969-806X(00)00430-8.

Barbalat, O. (1990). Applications of Particle Accelerators. In CERN Accelerator School: Fourth General Accelerator Physics Course (pp. 17-29). KFA, Julich, Fed. Rep. Germany.

Bhandari, R.K \& Malay Kanti Dey. (2011). Applications of accelerator technology and its relevance to nuclear technology. Energy Procedia, 7: 577-588.

Billenand, J. \& Young, L.M. (1987). Poisson Superfish Reference Manual. Los Alamos National Laboratory, New Mexico, USA. Report Number: LA-UR-96-1834.

Harbough, W.E. (1962). Tungsten, thoriated-tungsten, and thoria emitters. Electron Tube Design, Radio Corp. of America, Harrison, NJ, 90-98.

Herrmannsfeldt, W.B. (1997). Developments in the electron gun simulation. Physica Scripta, T71: 28-33.

Hoseinzade, M., Nijatie, A. \& Sadighzadeh, A. (2016). Numerical simulation and design of a thermionic electron gun. Chinese Physics C, $40 \quad$ (5): 057003. https://dx.doi.org/10.1088/1674-1137/40/5/057003. 
International Irradiation Association (IIA) (2011). Industrial Radiation with Electron Beams and X-rays. Revision 6.

Iqbal, M. \& Aleem, F. (2005). Theory and design of thermionic electron beam guns. In American Institute of Physics Conference Proceedings, 748: 376-386. https://dx.doi.org/10.1063/1.1896511.

Kalvas, T., Tarvainen, O., Ropponen, T., Steczkiewicz, O., Ärje J. \& Clark, H. (2010) IBSIMU: A three-dimensional simulation software for charged particle optics. Review of Scientific Instruments, 81:02B703 (1-3). https://dx.doi.org/10.1063/1.3258608.

Kogure, T. (2013). Electron microscopy. Developments in Clay Science, 5: 275-317. https://dx.doi.org/10.1016/B978-0-08098259-5.00011-1.

Lee, J.C., Kim, H., Ghergherehchi, M., Shin, S.W., Lee, Y.S., Yeon, Y.H., Lee, B.N. \& Chai, J. (2014). Design and analysis of an electron beam in an electron gun for $\mathrm{x}$-ray radiotherapy. In 5th International Particle Accelerator Conference, International Particle Accelerator Conference 2014; Dresden, Germany, pp. 688-691. https://dx.doi.org/10.18429/JACoW-IPAC2014-MOPRI040.

Machi, S., Yuan, H.C. \& Sevastyanov, Y.G. (1983). Isotopes and radiation for modern industry. International Atomic Energy Agency Bulletin; 25 (1): 11-14.

Munakata, C. \& Watanabe, H. (1962). A new bias method of an electron gun. Journal of Electron Microscopy, 11(1): 47-51. https://dx.doi.org/10.1093/oxfordjournals.jmicro.a049328.

Naieni, A.K., Bahrami, F., Yasrebi, N. \& Rashidian, B. (2009). Design and study of enhanced Faraday cup detector. Vacuum, 83: 1095-1099. https://dx.doi.org/10.1016/j.vacuum.2009.01.005.

Nazari, M., Abbasi, F., Ghasemi, F., Haghalab, S. \& Ahmadiannanim, S. (2017) Design, simulation and compare of flat cathode electron guns with spherical cathode electron guns for industrial accelerators. In Proceedings of International Particle Accelerator Conference 2017; Copenhagen, Denmark,. pp. 702-704.

Radio Corporation of America, Electron Tube Division. (1943) RCA HB-3 Electron Tube Handbook. Harrison, NJ, USA.

Scrivens, R. (2003). Electron and ion sources for particle accelerators. In CERN Accelerator School: Intermediate Accelerator Physics; Zeuthen, Germany. pp. 495-504. https://dx.doi.org/10.5170/CERN-2006-002.495.

Studer, N. (1990). Electron beam crosslinking of insulated wire and cable: Process economics and comparison with other technologies. International Journal of Radiation Applications and Instrumentation, Part C, 35 (4-6): 680-686.

The EuCARD-2 Collaboration. Applications of Particle Accelerators in Europe. (2017). Report number: CERN-ACC2020-0008.

Virag, M. \& Murin, J. (2008). Thermal field simulation of a tungsten filament lamp referring to its lifetime. Journal of Electrical Engineering, 56(9-10): 252-257.

Vretenar, M. (2005). Differences between electron and ion linacs. In CERN Accelerator School: Small Accelerators. (pp. 179-200). The Netherlands. https://dx.doi.org/10.5170/CERN2006-012. 